\title{
The progress of TMT Laser Guide Star Facility
}

\author{
Min $\mathrm{Li}^{1,2}$, Kai Wei ${ }^{1,2^{*}}$, Jinlong Tang ${ }^{1,2}$, Changchun Jiang ${ }^{1,2}$, Muwen Fan ${ }^{1,2}$, Feng Chen ${ }^{1,2}$, Daoman \\ Rui $^{1,2}$, Xiqi Li ${ }^{1,2}$, Corinne Boyer ${ }^{3}$, Lianqi Wang ${ }^{3}$,Brent Ellerbroek ${ }^{3}$, , Hao Xian ${ }^{1,2}$, Changhui Rao ${ }^{1,2}$ \\ and Yudong Zhang ${ }^{1,2}$ \\ ${ }^{1}$ Institute of Optics and Electronics (IOE), Chinese Academy of Sciences, Chengdu 610209, China; \\ ${ }^{2}$ The Key Laboratory on Adaptive Optics, Chinese Academy of Sciences, Chengdu 610209, China; \\ ${ }^{3}$ Thirty Meter Telescope Corporation (TMT), USA
}

\begin{abstract}
The Laser Guide Star Facility (LGSF) is responsible for generating the artificial laser guide stars required by the TMT Laser Guide Star (LGS) AO systems. The LGSF uses multiple sodium lasers to generate and project several LGS asterisms from a laser launch telescope located behind the TMT secondary mirror. The LGSF includes 3 main subsystems: (1) the laser system, (2) the beam transfer optics (BTO) system, (3) the associated laser safety system. At present, the LGSF is in the preliminary design phase. During this phase, the laser launch telescope trade study, Beam transfer optical path trade study are compared carefully, and some critical components prototypes have been carried out to verify the requirements, such as the polarization status control and test, the Fast Steer Mirror (FSM) prototype test.
\end{abstract}

Keywords: Laser Guide Star Facility, TMT, progress

\section{INTRODUCTION}

The Laser Guide Star Facility (LGSF) is responsible for generating artificial guide stars in the mesospheric sodium layer with the brightness, beam quality and asterism geometries required by both the NFIRAOS early light AO system and later $\mathrm{AO}$ instruments ${ }^{[1-6]}$.

The LGSF consists of 3 primary sub-systems:

- The Laser System, which includes up to nine 20-25W CW or pulsed sodium lasers mounted on inside of the XECRS telescope elevation journal.

- the Beam Transfer Optics (BTO) System, which is responsible for taking the beams at the output of the laser system and transferring them up the telescope elevation structure and then launching them from the LLT located behind the TMT secondary mirror. The BTO system is composed of two principal systems: (1) the Optical Path and (2) the LGSF Top End, which consists of the components located behind the TMT secondary mirror. The LGSF Top End includes the Diagnostic system, the Asterism Generator, the Laser Launch Telescope (LLT) and the Acquisition System.

- The Laser Safety System, which provides interlocks to prevent laser damage to personnel, the TMT observatory or the LGSF itself. In addition, the LGSF provides safety systems to avoid accidental illumination of aircraft and satellites, and to avoid beam collision with neighboring telescopes.

The layout of laser system and beam transfer optics system is shown in Figure 1. 


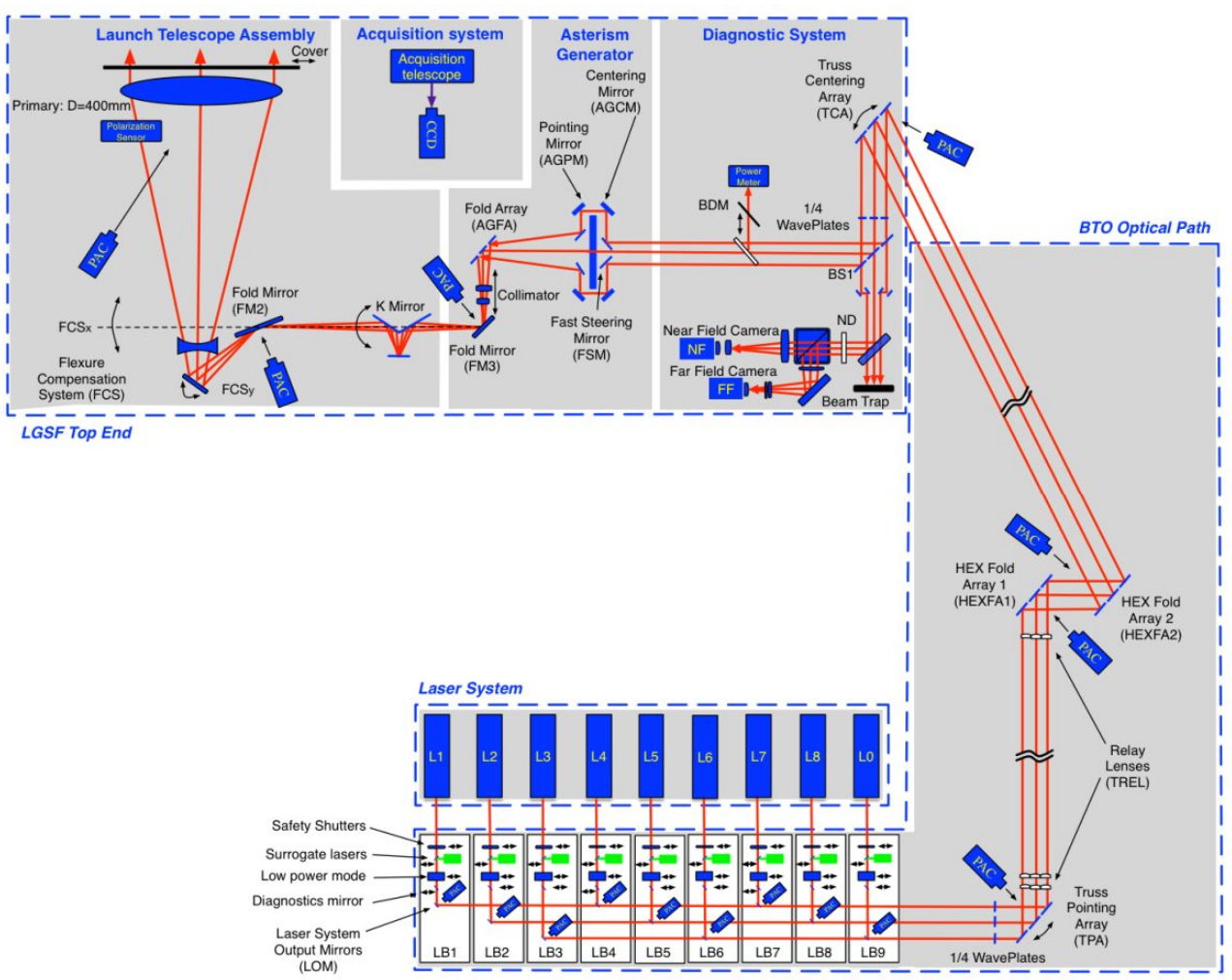

Figure 1. The layout of laser system and beam transfer optics system

The Institute of Optics and Electronics (IOE) in Chengdu (China) is the lead supplier and system integrator of the LGSF at TMT, and is directly responsible of the Laser Handling and Utilities sub-system of the Laser system, the Beam Transfer Optics and Laser Launch Telescope System and the Laser Safety System. The TMT LGSF design, manufacturing, testing and integration work is managed and carried out by IOE.

LGSF Conceptual Design starts at 01/10/2010. In 2010-2012, the design of the BTO and LLT system was updated by IOE, to take into account changes in the telescope structure design and to include new requirements. In 2011, IOE has a successfully review for the LGSF conceptual design update work to meet the new requirement. Since the telescope structure has been large modified by MELCO in 2012-2013, the LGSF has been updated again to meet changes of the telescope, which is focus on the top-end redesign the trade study of the optical path.

LGSF Preliminary Design (PD) Starts at 15/03/2014. During this phase, some critical components prototypes have been carried out to verify the requirements, such as the polarization status control along the BTO analysis and test, the Fast Steer Mirror (FSM) prototype test. Considering the structure tolerance, the laser launch telescope has been redesigned and the trade study has been done. So far, IOE has successfully passed four stages of review for the LGSF Preliminary design. In this paper, some main works in PD phase have been presented.

\section{TRADE STUDY}

Trade study is mainly focus on the items which have great changes relative to the previous design. During the preliminary design phase, the laser launch telescope trade study and Beam transfer optical path trade study are compared carefully. 


\subsection{Beam transfer optical path}

The Beam Transfer Optics System includes conventional (mirror-based) to avoid the issues associated with transmitting high power laser beam through optical fibers over relatively long distances. In 2012-2013, the telescope structure has been largely modified by MELCO, allowing a new option for the LGSF optical path. In this study, two optical paths were compared:

- The baseline OP, which was proposed during the conceptual design update work in 2011.

- The new OP, which was proposed in following the MELCO telescope structure redesign.

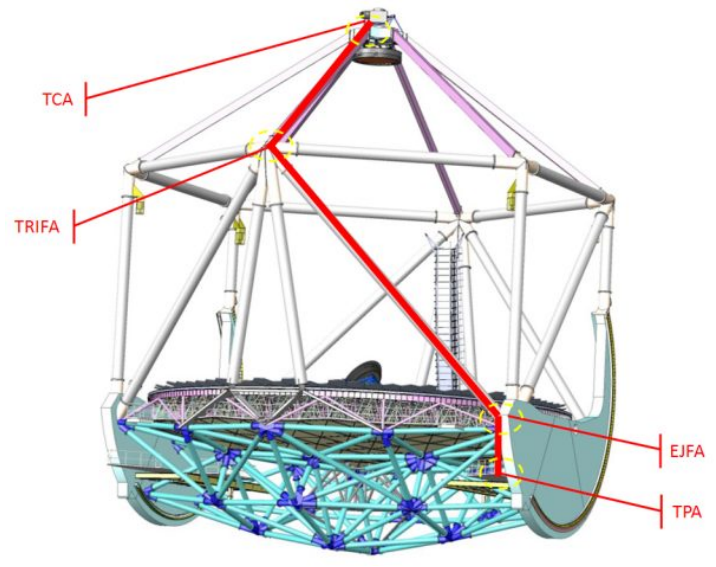

(a) The baseline OP

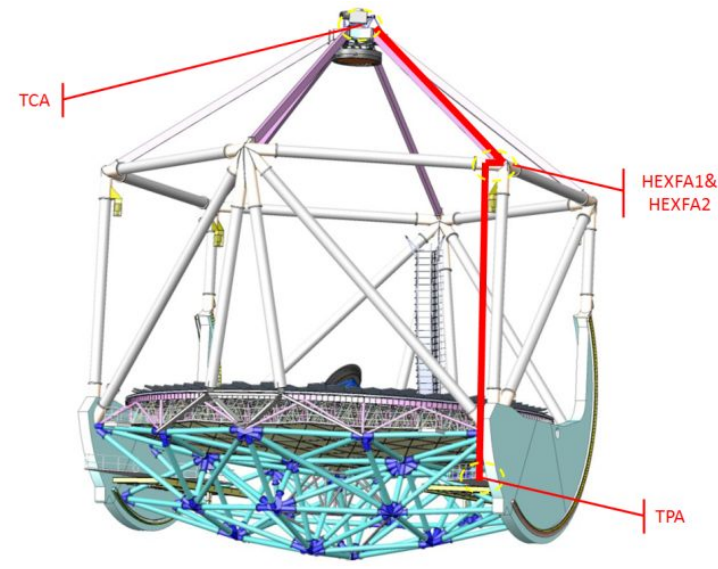

(b) The new OP

Figure 2. Optical path in the telescope structure design

Two optical paths are compared according to the following criteria: (1) Optical performance, (2) Mechanical design, (3) Access to LGSF components, (4) Interference with other observatory systems, (5) Telescope and LGSF performance.

Finally, the new OP is commented. The main reason is that:

- The angles of incident (AOI) of the folds are smaller, which will make the coating requirements easier and help with the throughput.

- The new OP has less potential interferences with other telescope systems.

The only disadvantage of the new OP is the larger beam displacement induced by the telescope deflection. But it can be compensated by activating three mirrors (LOM, TPA, TCA) or four mirrors (LOM, TPA, HEXFA2, TCA) along the BTO optical path.

\subsection{Laser launch telescope design}

The laser launch telescope implemented at first lights shall be upgradeable to project additional asterisms with up to 9 LGS and radii varying from 0 arcsec to 408 arcsec.

From 2006 to 2010, the laser launch telescope design has been updated four times by NOAO and TMT sub-contracted Optical Research Associates (ORA). In 2012, IOE chose one reflective design as the baseline design and updated it During the Preliminary Design (PD) Phase, it is found that the LLT reflective design has very tight optical tolerance and high risk during observation. In 2015, IOE start to think back again, to updates the refractive design. So it is need to do the trade study about the new reflective and refractive design.

The main requirements of laser launch telescope are shown in table 1. 
Table 1. main requirements of laser launch telescope

\begin{tabular}{|c|c|c|c|}
\hline subject & \multicolumn{3}{|l|}{ requirement } \\
\hline FOV & \multicolumn{3}{|c|}{ Should cover the latest GLAO field } \\
\hline \multirow[t]{5}{*}{ Performance } & \multirow{2}{*}{ Error Term } & \multicolumn{2}{|c|}{ LGSF(BTO+LLT)RMS WFE, nm } \\
\hline & & *Requirement & Goal \\
\hline & Optical misalignment & $60(0.1 \lambda)$ & $40(\lambda / 15)$ \\
\hline & Surface irregularity & $30(0.05 \lambda)$ & $20(\lambda / 30)$ \\
\hline & RSS & $67(0.114 \lambda)$ & $34(0.058 \lambda)$ \\
\hline Telescope azimuth angle changes & \multicolumn{3}{|l|}{ from $0^{\circ}$ to $65^{\circ}$} \\
\hline Temperature changes & \multicolumn{3}{|l|}{ from $-5^{\circ} \mathrm{C}$ to $9^{\circ} \mathrm{C}$} \\
\hline Throughput & \multicolumn{3}{|l|}{$0.88($ Goal $>0.9)$} \\
\hline Aperture & \multicolumn{3}{|l|}{$0.4 \mathrm{~m}$} \\
\hline
\end{tabular}

Based on the previous design, IOE has developed two new LLT designs: reflective and refractive. The specific optical structures are shown in figure 3. The structure mainly contains: primary mirror, second mirror, $\mathrm{K}$ mirror and Collimate lens. The magnification of LLT is 48 . For the reflective design, the primary mirror is a paraboloid mirror and the second mirror is a hyperboloid mirror. For the refractive design, the primary lens is a lens with Ellipsoid aspheric surface.

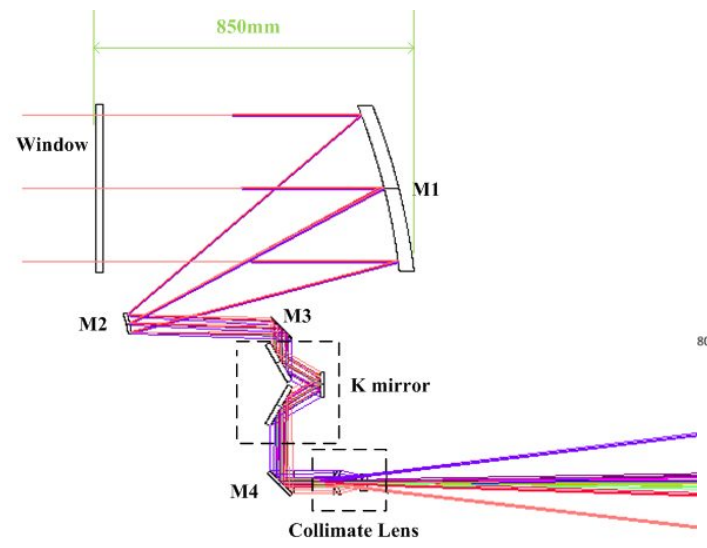

(a) Reflective design (Paraboloid- Hyperboloid)

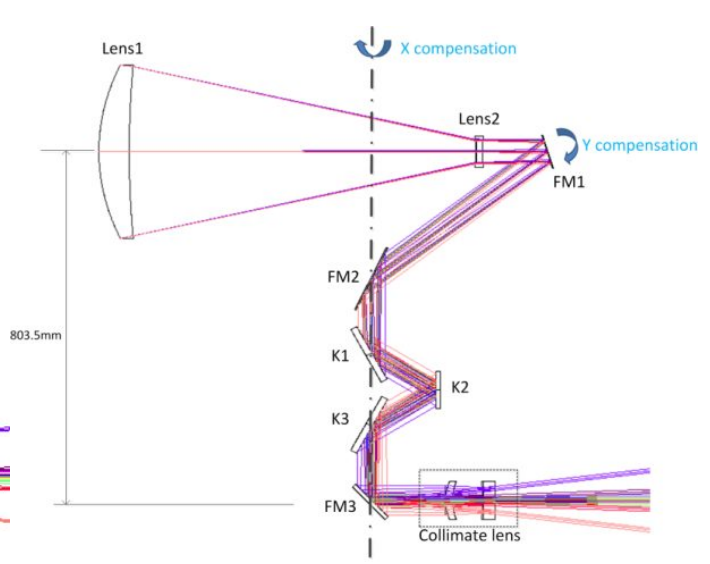

(b) Refractive design

Figure 3. Laser launch telescope optical design

The optical performance of LLT is shown in figure 4. They are nearly the same for the two designs over the requirement fields. 


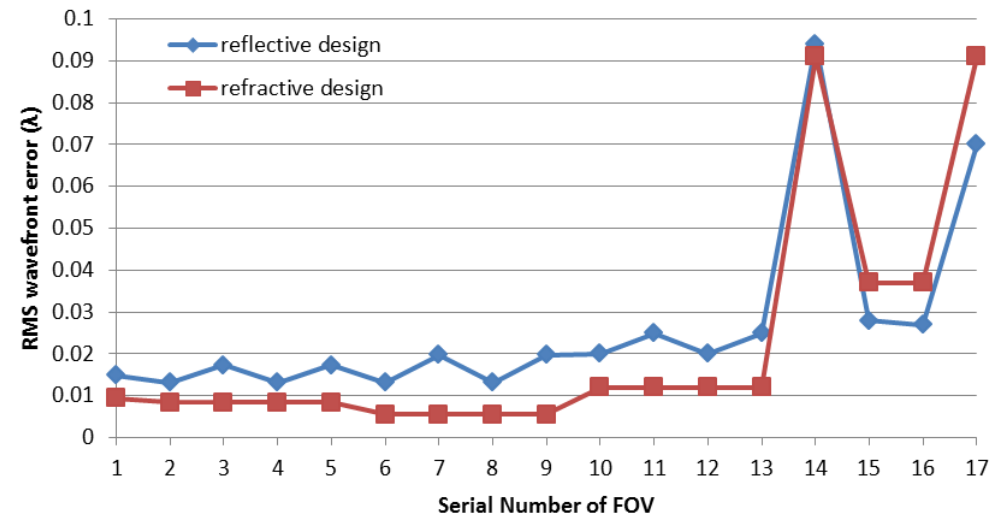

\begin{tabular}{|c|c|c|c|c|c|c|c|c|c|c|c|c|c|c|c|c|c|}
\hline Serial & 1 & 2 & 3 & 4 & 5 & 6 & 7 & 8 & 9 & 10 & 11 & 12 & 13 & 14 & 15 & 16 & 17 \\
\hline FOV(arcsec) & 0 & $35(+x,+y)$ & $35(+x,-y)$ & $35(-x,+y)$ & $35(-x,-y)$ & $70(+x,+y)$ & $70(+x,-y)$ & $70(-x,+y)$ & $70(-x,-y)$ & $150(+x,+y)$ & $150(+x,-y)$ & $150(-x,+y)$ & 150 & $\begin{array}{c}408(x) \\
279(y)\end{array}$ & $\begin{array}{l}168(X) \\
279(y)\end{array}$ & $\begin{array}{l}168(X), \\
-279(y)\end{array}$ & $\begin{array}{l}408(x) \\
-279(y)\end{array}$ \\
\hline
\end{tabular}

Figure 4. Optical performance of Laser launch telescope

The mechanical structure of LLT is shown in figure 5. The deformation performance of LLT has been simulated when the zenith angle and temperature changed. The results are presented in table 2 and table 3 . The refractive design is more attractive.

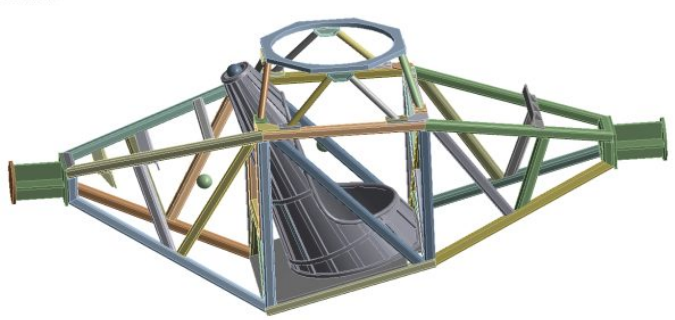

(a)reflective design

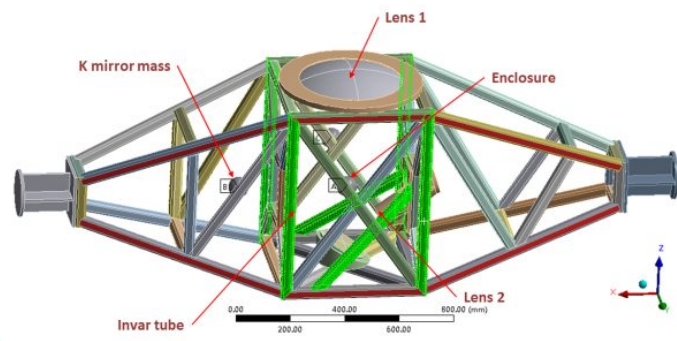

(b)refractive design

Figure 5. Mechanical structure of Laser launch telescope

Table 2. deformation performance of Reflective LLT

\begin{tabular}{|l|l|l|l|l|}
\hline & $\begin{array}{l}\text { Actual RMS } \\
\text { result } \\
\text { (before } \\
\text { compensation) }\end{array}$ & $\begin{array}{l}\text { Actual RMS } \\
\text { result } \\
\text { (after } \\
\text { compensation) } \\
\text { Tolerance } \\
\text { (RMS) }\end{array}$ & $\begin{array}{l}\text { Compensator: } \\
\text { distance } \\
\text { between } \\
\text { and lens2 } \\
\text { lens }\end{array}$ \\
\hline $\begin{array}{l}0^{\circ}-30^{\circ} \text { Zenith when the } \\
\text { temperature no change }\end{array}$ & $35.3 \mathrm{~nm}$ & $11.2 \mathrm{~nm}$ & $29.35 \mathrm{~nm}$ & $1.65 \mathrm{~mm}$ \\
\hline $\begin{array}{l}0^{\circ}-30^{\circ} \text { Zenith when the } \\
\text { temperature change from } 9 \\
{ }^{\circ} \mathrm{C} \text { to }-5^{\circ} \mathrm{C}\end{array}$ & $74.2 \mathrm{~nm}$ & $15.9 \mathrm{~nm}$ & $3.67 \mathrm{~mm}$ \\
\hline $\begin{array}{l}0^{\circ}-65^{\circ} \mathrm{Zenith} \mathrm{when} \mathrm{the} \\
\text { temperature no change }\end{array}$ & $159 \mathrm{~nm}$ & $20 \mathrm{~nm}$ & $8 \mathrm{~mm}$ \\
\hline $\begin{array}{l}0^{\circ}-65^{\circ} \mathrm{Zenith} \mathrm{when} \mathrm{the} \\
\text { temperature change from } 9 \\
{ }^{\circ} \mathrm{C} \text { to }-5^{\circ} \mathrm{C}\end{array}$ & $76.6 \mathrm{~nm}$ & $21.8 \mathrm{~nm}$ & & $3.6 \mathrm{~mm}$ \\
\hline
\end{tabular}


Table 3. deformation performance of Refractive LLT

\begin{tabular}{|l|l|l|l|l|}
\hline & $\begin{array}{l}\text { Actual RMS } \\
\text { result } \\
\text { (before } \\
\text { compensation) }\end{array}$ & $\begin{array}{l}\text { Actual RMS } \\
\text { result } \\
\text { (after } \\
\text { compensation) }\end{array}$ & $\begin{array}{l}\text { Require } \\
\text { Tolerance } \\
\text { (RMS) }\end{array}$ & $\begin{array}{l}\text { Compensator: } \\
\text { distance } \\
\text { between } \\
\text { and } \\
\text { collimator }\end{array}$ \\
\hline $\begin{array}{l}0^{\circ}-30^{\circ} \text { Zenith when the } \\
\text { temperature no change }\end{array}$ & $36.52 \mathrm{~nm}$ & $22.97 \mathrm{~nm}$ & $29.45 \mathrm{~nm}$ & $1 \mathrm{~mm}$ \\
\hline $\begin{array}{l}30^{\circ}-65^{\circ} \mathrm{Zenith} \text { when the } \\
\text { temperature change from } \\
9^{\circ} \mathrm{C} \text { to }-5^{\circ} \mathrm{C}\end{array}$ & $35.93 \mathrm{~nm}$ & $21.2 \mathrm{~nm}$ & $1 \mathrm{~mm}$ \\
\hline $\begin{array}{l}0^{\circ}-65^{\circ} \mathrm{Zenith} \mathrm{when} \mathrm{the} \\
\text { temperature no change }\end{array}$ & $10 \mathrm{~nm}$ & $23.56 \mathrm{~nm}$ & no & $1.1 \mathrm{~mm}$ \\
\hline $\begin{array}{l}0^{\circ}-65^{\circ} \mathrm{Zenith} \mathrm{when} \mathrm{the} \\
\text { temperature change from } \\
9^{\circ} \mathrm{C} \text { to }-5^{\circ} \mathrm{C}\end{array}$ & $37.11 \mathrm{~nm}$ & & & \\
\hline
\end{tabular}

At the same time, the tight optical tolerance of reflective LLT has been considered. It is reflected at the part of axis shift compensation for reflective LLT. In the reflective LLT design, a so-called zero Coma point has been used to pivot M2 to rotate with to compensate the $\mathrm{X}$ axis shift caused by the telescope flexure. The compensation principle is shown in figure 6. This is the most difficult part for the reflective LLT. Because the tolerance of the Zero Coma Point is quite tight to realize, which is $0.0001 \mathrm{~mm}$ at $\mathrm{X}$ axis decenter, $0.0003^{\circ}$ at $\mathrm{X}$ tilt and $0.00075^{\circ}$ at $\mathrm{Y}$ tilt.

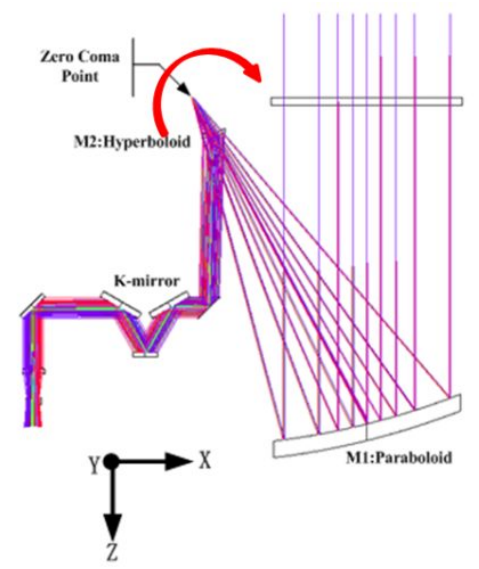

Figure 6. X axis shift compensation by pivoting M2 to rotate with Zero Coma Point

After comparing the optical performance, mechanical design and risk analysis, the Refractive design is adopted. And the specific design will be developed at the next phase. 


\section{PROTOTYPE TEST}

In the Preliminary Design (PD) Phase, many targets required need to be confirmed. So some critical components prototypes have been carried out to support the design and performance of the sub-system.

\subsection{Polarization status control}

According to the requirement, the LGSF system shall generate laser guide stars which are $98 \%$ circularly polarized. To meet the requirement, the best situation for the reflector is that there is no phase difference between $\mathrm{S}$ wave and $\mathrm{P}$ wave and reflectivity is almost to 1 . During the real coating procedure, it is easier to control the reflectivity but hard and more expensive to control the phase difference for the $\mathrm{S}$ wave and $\mathrm{P}$ wave. An initiative compensation method has been used to get the polarization target. It is to use two quarter wave plate to compensate the polarization status.

First, a polarization physical model is built to simulate the polarization state of LGSF. It can provide a guideline to our design and analysis. But it needs to be validated. So a polarization test model is built in our lab. The picture for the polarization test bench is shown in figure 7.The beam comes out from the laser and then goes through the Polarizer, two 1/4 WPs, LOM, TPA, HEXFA1\&2, TCA,BS and finally enters into the Polarimetry. The AOI of each mirror are the same as TMT LGSF optical path. The detail angel and information for each mirror is shown in table 4 .

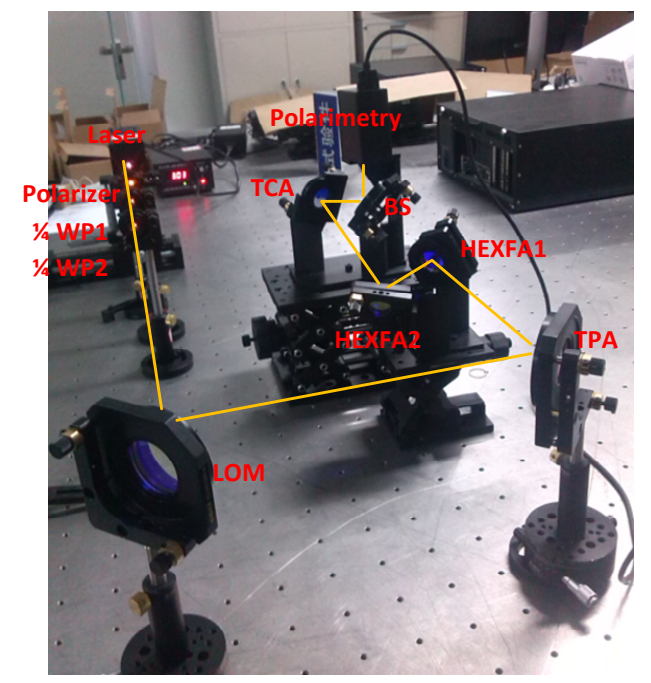

Figure 7. picture of LGSF test model

Table 4. The detail angel and information for each mirror

\begin{tabular}{|c|c|c|c|c|c|c|}
\hline & $\begin{array}{c}\text { Designed } \\
\text { coating } \\
\text { angle( }\end{array}$ & $\begin{array}{c}\text { Actual } \\
\text { Incident } \\
\text { angle (" ) }\end{array}$ & $R_{S}$ & $R_{P}$ & $\varphi_{S}-\varphi_{P}$ & $\begin{array}{c}\text { plane } \\
\text { rotation } \\
\text { angle } \theta \\
\mathbf{(}^{\mathbf{*}} \text { ) }\end{array}$ \\
\hline LOM & 45 & 45 & 0.995 & 0.957 & 50 & 0 \\
\hline TPA & 45 & 45 & 0.995 & 0.957 & 50 & 0 \\
\hline HEXFA1 & 30 & 45 & 0.995 & 0.883 & 40 & -149.024 \\
\hline HEXFA2 & 30 & 44.6 & 0.995 & 0.883 & 40 & -234.996 \\
\hline TCA & 30 & 31 & 0.995 & 0.957 & 87.4 & 32.817 \\
\hline BS & 30 & 47.9 & 0.995 & 0.883 & 40 & -175.9 \\
\hline
\end{tabular}

The experimental results and the theoretical results using two quarter wave plates are both plot in figure 8 . The $\mathrm{X}$ axis is presented the rotation angle of quarter wave plate $1, \mathrm{Y}$ axis is presented the rotation angle of quarter wave plate 2 . The 
red dot is presented the theoretical results when circular polarization ratio is greater than 0.98 . The blue dot is presented the experimental results when circular polarization ratio is greater than 0.98 .

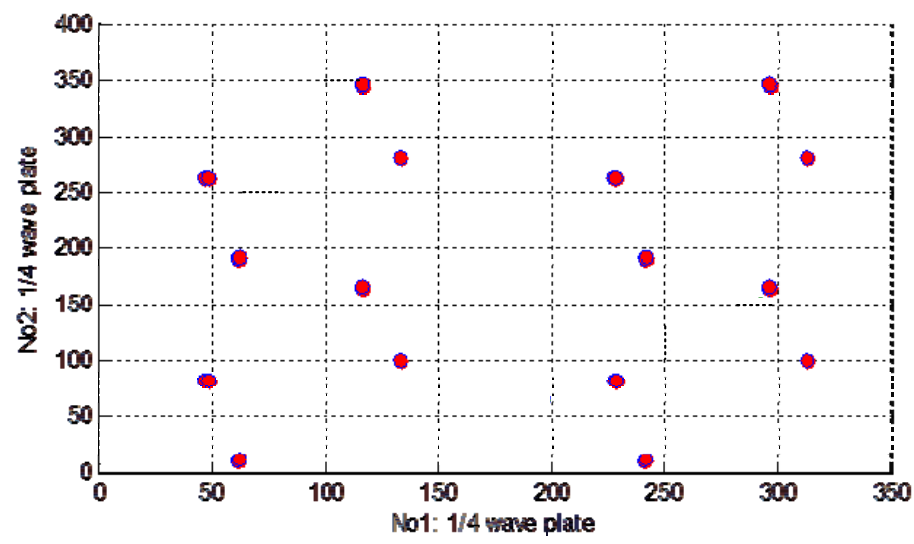

Figure 8 . The experimental results and the theoretical results using two quarter wave plates

The results tell that two quarter wave plates can do this job perfectly and also have many combinations both in the theoretical analysis and experimental test.

\subsection{Fast steer mirror test}

The BTO includes an automated fast steering mirror for each laser beacon to maintain stable laser pointing and to compensate for turbulence-induced pointing error. The requirements about the bandwidth, dynamic range of fast steer mirror need to be meet. So the performance characteristics of the FSM prototype have to be examined.

The baseline of FSM is S-330.2SL platform from Physik Instruments (PI) which contains an E-509.S3 Strain Gauge Sensor (SGS) to form a closed-loop system to ensure the position precision, and the E-503 amplifier module to drive the piezo-electricity actuators. An E-500.00 chassis can provide driver electronics for 3 FSMs. The driver electronics is an analogue topology.

This paper just focuses on the dynamic frequency response of the FSM during the FSM prototype test phase 1.

Given an input sine wave voltage with a fix voltage $(0.5 \mathrm{~V})$ and different frequency sweeping from $0.5 \mathrm{~Hz}$ to $2000 \mathrm{~Hz}$, measuring the tip/tilt angle by the high speed electronic autocollimator, then get a frequency response based on the dynamic analyzer. The dynamic performance test platform configuration is shown in the following figure 9 .

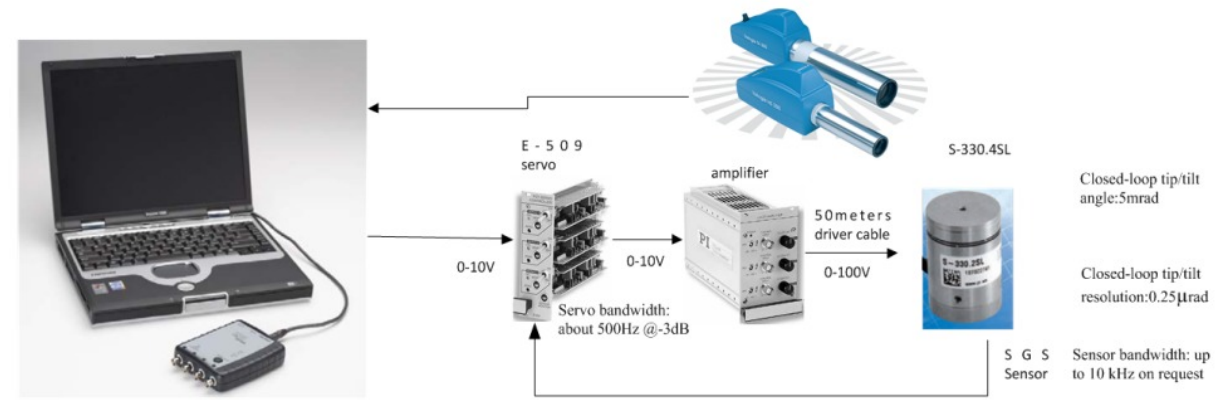

Figure 9. dynamic performance test platform configuration

The FSMs are attached to the AG radial bench at four different directions when telescope points to zenith. It is shown in figure 10. So, all the four FSM gravity direction are tested. And at the same time, the different mounting structures with different material (steel or aluminum) are test. The dynamic frequency response results are shown in the table 5. 


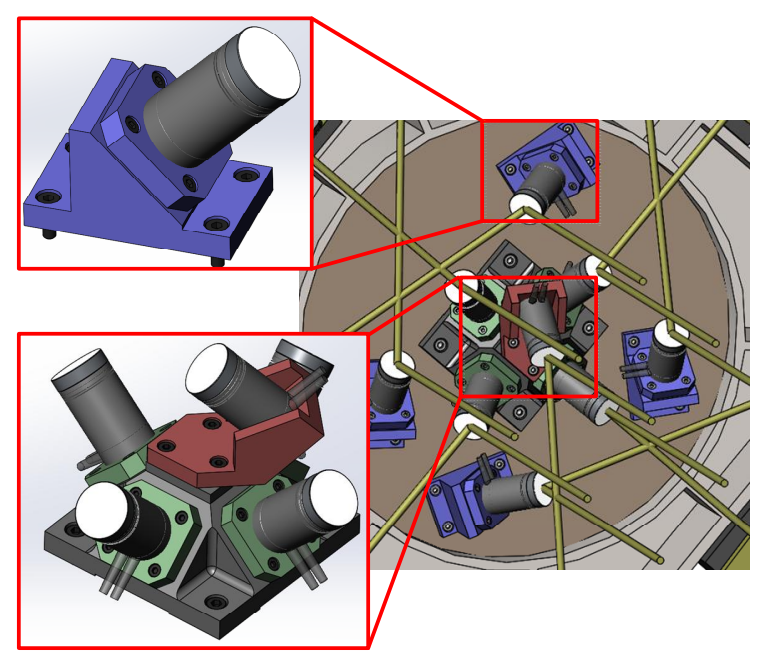

Figure 10: FSM location of AG when telescope points to zenith $0^{\circ}$

Table 5. dynamic frequency response results

\begin{tabular}{|c|c|c|c|c|}
\hline NO. & FSM direction & Mounting structure & Axis & Resonant frequency \\
\hline \multirow[t]{2}{*}{1} & \multirow[t]{2}{*}{0 degree } & \multirow[t]{2}{*}{ / } & $\mathrm{X}$ & $704 \mathrm{~Hz}$ \\
\hline & & & $\mathrm{Y}$ & $1500 \mathrm{~Hz}$ \\
\hline \multirow[t]{4}{*}{2} & \multirow[t]{4}{*}{90 degree } & \multirow[t]{2}{*}{ Aluminum } & $\mathrm{X}$ & $676 \mathrm{~Hz}, 1130 \mathrm{~Hz}$ \\
\hline & & & $\mathrm{Y}$ & $728 \mathrm{~Hz}$ \\
\hline & & \multirow[t]{2}{*}{ Steel } & $X$ & $767 \mathrm{~Hz}, 1340 \mathrm{~Hz}$ \\
\hline & & & $\mathrm{Y}$ & $832 \mathrm{~Hz}$ \\
\hline \multirow[t]{4}{*}{3} & \multirow[t]{4}{*}{45 degree } & \multirow[t]{2}{*}{ Aluminum } & $X$ & $1130 \mathrm{~Hz}$ \\
\hline & & & $\mathrm{Y}$ & $1020 \mathrm{~Hz}$ \\
\hline & & \multirow[t]{2}{*}{ Steel } & $\mathrm{X}$ & $1450 \mathrm{~Hz}$ \\
\hline & & & $\mathrm{Y}$ & $1040 \mathrm{~Hz}$ \\
\hline \multirow[t]{4}{*}{4} & \multirow[t]{4}{*}{-45 degree } & \multirow[t]{2}{*}{ Aluminum } & $\mathrm{X}$ & $956 \mathrm{~Hz}$ \\
\hline & & & $\mathrm{Y}$ & $872 \mathrm{~Hz}$ \\
\hline & & \multirow[t]{2}{*}{ Steel } & $\mathrm{X}$ & $1140 \mathrm{~Hz}$ \\
\hline & & & $\mathrm{Y}$ & $932 \mathrm{~Hz}$ \\
\hline
\end{tabular}

It is shown that the resonant frequency of the steel mounting structure is higher than that of the aluminum mounting structure in all four FSM gravity directions. The resonant frequencies of the four FSM gravity directions are relatively high (more than $650 \mathrm{~Hz}$ ). It is difficult to find the optimal gravity direction since the test beam paths are different.

Also, the influence of the position of FSM controller carbinet is considered. If it is at the top end, the length of cable is about $1.5 \mathrm{~m}$. If it is at the laser bench, the length of is about $50 \mathrm{~m}$. Whether the long driver cable will influence the ability of FSM? So the dynamic frequency responses under 50 meters driver cable or 1.5 meters driver cable are tested at FSM 0 degree gravity direction. The test result is shown in figure 11. 


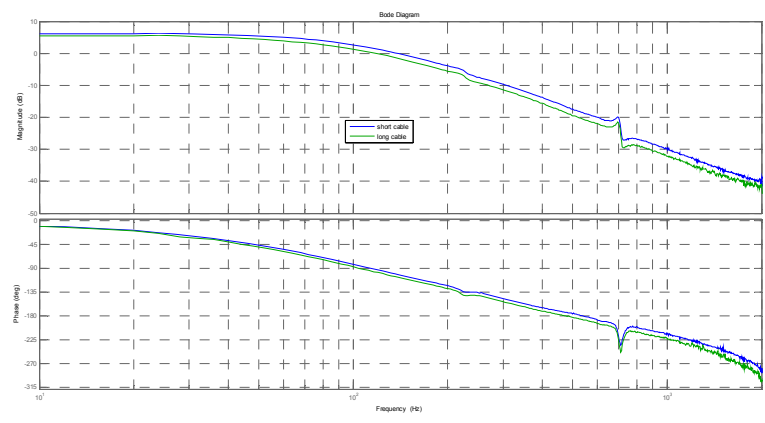

(a) $\mathrm{x}$ axis: frequency response

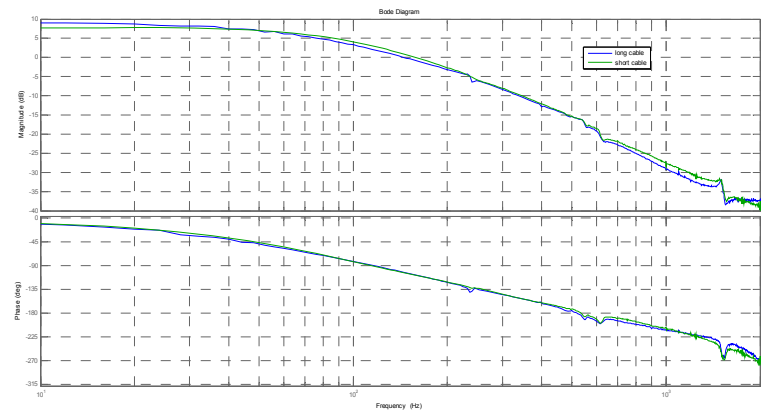

(b) y axis: frequency response

Figure 11: dynamic frequency response under different length driver cable

It has no obvious difference at dynamic frequency response in the $2000 \mathrm{~Hz}$ frequency range under different length cable.

\section{CONCLUSIONS}

At the Preliminary Design (PD) Phase, some sufficiently detailed designs have been done to demonstrate that (1) the design and interface requirements are met; (2) all significant design choices are made; (3) major risks are retired. It needs to demonstrate a design and the outline of associated process resulting in the product as defined. Now the LGSF design

is at the stage of PD 5. There are still some works to do, such as the alignment plane, displacement budget, AG structure design, etc.

\section{REFERENCES}

1. G. Sanders and J. Nelson, "The status of the Thirty Meter Telescope project", Proc. SPIE 7733-69 (2010).

2. L. Simard, C. Boyer, D. Crampton, and B. Ellerbroek, "The TMT Instrumentation Program," Proc. SPIE 7735-73 (2010).

3. G. Z. Angeli, S. Roberts, and K. Vogiatzis, "System Engineering for the Thirty Meter Telescope," Proc. SPIE 773845 (2010).

4. Stepp, Larry M., Sanders, G. H., “Thirty Meter Telescope project,” Proc. SPIE 8447, (2012).

5. Simard, L., et al, "The instrumentation program for the Thirty Meter Telescope," Proc. SPIE 8447, (2012).

6. L. Simard and D. Crampton, "Science Flowdown for the Thirty Meter Telescope," Proc. SPIE 7735-213 (2010). 